\title{
Antropologia como locus da espiritualidade: Considerações não dualistas sobre a espiritualidade cristã
}

\author{
Anthropology as a locus of spirituality: \\ Non-dualistic considerations about Christian \\ spirituality
}

Alessandro Rocha

\section{Resumo}

$\mathrm{O}$ artigo "Antropologia como locus da espiritualidade. Considerações não dualistas sobre a espiritualidade cristã", discute a espiritualidade que pode emergir de um aporte antropológico que pensa a realidade de forma integrada. Em primeiro momento há uma reflexão sobre como somos criados humanos, mas vocacionados à humanidade, ou seja, como a humanização é um processo que só poderá ocorrer como projeto. Em seguida é apontada a ontologia fraca como gênese da construção de uma espiritualidade integrada. Por fim, figura uma reflexão sobre as dimensões do que poderia ser chamado da espiritualidade humanizada ou da humanidade espiritualizada.

Palavras-chave: Espiritualidade. Antropologia teológica. Pensamento fraco.

\section{Abstract}

The paper "Anthropology as a locus of spirituality. Non-dualistic considerations about Christian spirituality", discusses the spirituality that can emerge from an anthropological contribution think reality in an integrated manner. At first there is a reflection we created humans, but devoted to 
humanity, that is, how the humanization is a process that can only occur as project. Then is pointed to the weak ontology as a Genesis of the construction of an integrated spirituality. Finally, figure a reflection about the dimensions of what might be called humanized or spirituality of mankind Spiritualized.

Keywords: Spirituality. Theological Anthropology. Thought weak.

\section{Introdução}

Falar sobre espiritualidade tem sido uma prática cada vez mais constante nas diversas igrejas, corporações e também nas mais variadas mídias, quer sejam seculares ou religiosas. Contudo, embora isso possa parecer um fenômeno atual, o conteúdo subjacente a tais discursos oferece pouca novidade. Basicamente se fala de espiritualidade como sendo uma expressão do espírito humano em relação a Deus, expressão que ocorre sobre os escombros da matéria (cultura e história), que é quase sempre tomado como empecilho ao maior desenvolvimento da santidade.

Esse não é mais do que o requentamento de velhas matrizes dualistas que têm influenciado o pensamento ocidental desde os dias de Platão. Contrário a esta tendência queremos posicionar esse texto buscando recuperar expressões da antropologia e da espiritualidade bíblicas em diálogo com a filosofia e a ontologia pós-modernas.

Para tanto seguiremos o caminho da afirmação da necessidade do humano para o cultivo do espiritual. Isso significa afirmar a humanização como caminho para a espiritualidade. Somos criados humanos e vocacionados à humanidade e, ao longo de tal vocação experimentamos o caminho espiritual como conatural à nossa própria existência. Tal olhar exige que se perceba na gênese do humano uma ontologia fraca que consiga superar os vícios da tradição metafísica e, com ela, a compreensão do ser humano como um ser fixado e solitário. Dessa forma será possível percorrer o caminho que poderá nos conduzir da simples hominização à complexa e necessária humanização, de onde efetivamente pode emergir uma espiritualidade atenta à grande jornada da existência. 


\section{Criados humanos, vocacionados à humanidade}

Quando contemplo os teus céus, obra dos teus dedos, a lua e as estrelas que estabeleceste, que é o homem, para que te lembres dele? E o filho do homem, para que o visites? Contudo, pouco abaixo de Deus o fizeste; de glória e de honra o coroaste. Deste-lhe domínio sobre as obras das tuas mãos; tudo puseste debaixo de seus pés: todas as ovelhas e bois, assim como os animais do campo, as aves do céu, e os peixes do mar, tudo o que passa pelas veredas dos mares. ${ }^{1}$

A pergunta do salmista faz uma remissão à teologia da criação e, nela, à vocação humana, ao desejo amoroso de Deus para seus filhos e filhas. Tal pergunta indica para o homem e a mulher concretos, eu e você que vivemos aqui ou ali, que sentimos e choramos, que vivemos e morremos. A literatura sapiencial não se constitui numa tentativa de teorização universal sobre o humano como o "animal político" de Aristóteles, o "contratante social" de Rousseau ou o "homo sapiens" de Lineu. ${ }^{2}$

A pergunta pelo homem e por aquilo que ele é precisa, portanto, ser dirigida a uma antropologia teológica e filosófica que considerem o existencial como espaço definitivo da realização humana em todas as suas dimensões. Aqui a reflexão de Miguel de Unamuno é bastante iluminadora.

Homo Sum; nihil humani a me alienum puto, disse o cômico larino. Eu diria melhor: Nullum hominem a me alienum puto. Sou homem: nenhum outro homem considero estranho. Porque o adjetivo humanus me é tão suspeito quanto o substantivo abstrato humanitas, humanidade. Nem o humano, nem a humanidade, nem o adjetivo simples, nem o adjetivo substantivado, mas sim o substantivo concreto: o homem. O homem de carne e osso, aquele que nasce, sofre e morre - sobretudo morre - que come, bebe, joga, dorme, pensa e ama, o homem que se vê e a quem se ouve, o irmão, o verdadeiro irmão. Porque há outra coisa, a que também chamam homem e que é o sujeito de não poucas divagações mais ou menos científicas. É o bípede implume da lenda, o Zoom politikon de Aristóteles, o contratante social de Rousseau, o homo oeconomicus dos manchestereanos, o homo sapiens de Lineu, ou, se preferirem, o mamífero

\footnotetext{
${ }^{1}$ Salmo 8.3-9. Grifo nosso.

${ }^{2}$ Para um aprofundamento na antropologia bíblica há dois livros que podem ajudar muito: WOLFF, H. W. Antropologia do Antigo Testamento. São Paulo: Hagnos, 2007; WÉNIN, A. O Homem Bíblico. Leituras do Primeiro Testamento. São Paulo: Loyola, 2015.
} 
vertical. Um homem que não é daqui ou dali, desta ou de outra época, que não tem sexo nem pátria - uma idéia, enfim. Isto é, um não-homem. $O$ nosso é outro, o de carne e osso: eu, você, meu leitor, aquele outro de mais além, todos os que pisamos sobre a terra. ${ }^{3}$

Estamos diante de uma reflexão sobre o ser concreto que se pode ver o rosto, que existe de fato. Inspirados na literatura bíblica, interessa aqui falar do homem e da mulher de carne e osso, dos seres viventes, das criaturas filiais de Deus que as fez à sua imagem e semelhança. Somente diante de criaturas reais é que podemos pensar a vocação como com-vocação, como chamado à realização de uma condição doada que precisa ser realizada no caminho existencial de cada homem e mulher.

E disse Deus: Façamos o homem à nossa imagem, conforme a nossa semelhança; domine ele sobre os peixes do mar, sobre as aves do céu, sobre os animais domésticos, e sobre toda a terra, e sobre todo réptil que se arrasta sobre a terra. Criou, pois, Deus o homem à sua imagem; à imagem de Deus o criou; homem e mulher os criou. ${ }^{4}$

A abordagem antropológica feita no salmo 8 está diretamente relacionado com a narrativa do livro de Gênesis; sobretudo, com os primeiros capítulos que tratam da criação. Somos vocacionados desde a criação para o pleno desenvolvimento de nosso ser. Fomos criados homens e mulheres. Mesmo antes de explorar as possibilidades hermenêuticas da imago Dei, é preciso pensar o que significa a condição humana, pois é nela que existimos e é nela que somos com-vocados às múltiplas vivências que podem nos constituir seres em processo humanização.

Nossa vocação é à humanidade, somente nesse espaço existencial concreto é que podemos realizar nosso ser. Somente aí é que poderemos alcançar a maturidade da existência que a tradição cristã convencionou chamar de espiritualidade. Só no espaço da humanidade pode ocorrer a espiritualidade. Aceitar tal missão - de ser humano - tem sido ao longo da história o maior desafio posto à frente de homens e mulheres.

Desde o início de nossa condição de seres-no-mundo aceitar a vocação à humanidade é o rito de iniciação principal ao acesso da vida madura.

\footnotetext{
${ }^{3}$ UNAMUNO, M. Do sentimento trágico da vida. São Paulo: Martins Fontes, 2000, pp. 1-2.

${ }^{4}$ Gênesis 1.26-27. Grifo nosso.
} 
Quem sabe seja exatamente por isso que a tentação mais primitiva seja a tentativa de alienação da própria condição humana. ${ }^{5}$ "A serpente disse então à mulher: Não, não morrereis! Mas Deus sabe que, no dia em que dele comerdes, vossos olhos se abrirão e vós sereis como deuses, versados no bem e no mal". ${ }^{6}$

"Vós sereis como deuses"! Aí se encontra a mais primitiva das tentações, aquela capaz de alienar o homem de si mesmo. ${ }^{7} \mathrm{O}$ que parece é que tal tentação encontra suas melhores acolhidas exatamente nos meios onde se cultiva a religião. $\mathrm{O}$ desejo de ser mais do que aquilo para o qual se foi vocacionado é encoberto por certa capa religiosa e, equivocadamente chamado de santidade. Neste caso, ser santo é ser não humano, é ser transhumano, é ser "espiritual".

O pecado, tão alardeado nos discursos religiosos, precisa ser repensado, não somente em perspectiva moral, mas também em nível ontológico. ${ }^{8} \mathrm{O}$ que é o pecado senão a alienação da condição criatural de humanos. Pecar é querer ser como deuses, ou seja, querer ser mais ou menos que humano. E ainda mais, pecado é desejar se furtar daquilo que constitui o próprio humano, a saber: as possibilidades e ambiguidades, as promessas e as frustrações, o horizonte e a falibilidade existencial. Pecado é querer ser não-humano. ${ }^{9}$

E espiritualidade, o que é então? Para ser coerente com nossa argumentação, ser espiritual é ser humano nos limites do que isso significa, é desenvolver a humanidade em suas máximas possibilidades - inclusive no que diz respeito às ambiguidades. Fomos criados do "pó da terra", ou seja, somos criados da e para a vida mundana. Espiritualidade é, portanto, exalar o cheiro da terra.

\footnotetext{
${ }^{5}$ Uma importante reflexão sobre essa temática encontra-se em: COX, H. Que a serpente não decida por nós. Rio de Janeiro: Civilização Brasileira, 1970.

${ }^{6}$ Gênesis 3.4-5. Grifo nosso.

${ }^{7}$ COX, H. Que a serpente não decida por nós. Rio de Janeiro: Civilização Brasileira, 1970, p. 12.

${ }^{8}$ Uma obra significativa sobre essa questão é a do rabino Nilton Bonder onde, através da linguagem sapiencial própria da tradição cabalística, ele recoloca uma série de questões sobre a compreensão de pecado fixada ao longo da tradição religiosa de corte moralista. Cf. BONDER, N. Código penal celeste: prepare sua defesa diante do Tribunal Supremo. Rio de Janeiro: Elsevier, 2004.

${ }^{9}$ BONDER, N. Código penal celeste: prepare sua defesa diante do Tribunal Supremo. Rio de Janeiro: Elsevier, 2004, p. 30.
} 


\section{Na gênese do humano uma ontologia fraca}

A pós-modernidade marca a superação da modernidade dirigida pelas concepções unívocas dos modelos fechados, tanto sobre a realidade humana, quanto acerca do próprio Deus. Ela é a passagem do pensamento forte, metafísico, das cosmovisões filosóficas universais, das crenças verdadeiras, ao pensamento fraco, a uma ontologia fraca. A condição humana é pensada a partir do pensiero debole ${ }^{10}$, um pensamento da diversidade, profundamente inserido no universo hermenêutico que relativiza a realidade em sua dimensão mais radical: a ontologia.

Esse caminho do pensamento fraco pelas sendas da hermenêutica é descrito pelo filósofo italiano Gianni Vattimo nos seguintes termos: "a) $\mathrm{O}$ conhecimento é sempre interpretação e nada mais que isso". ${ }^{11}$ "b) Ainterpretação é o único fato de que podemos falar [...] Na interpretação dá-se o mundo, não há apenas imagens 'subjetivas'. Mas o ser (a realidade ôntica) das coisas é inseparável do ser-aqui homem". ${ }^{12}$ "c) A interpretação, quanto mais queremos captá-la em sua autenticidade , mais ela se revela como eventual, histórica" ${ }^{13}$ “d) Se mesmo o fato de que não existem fatos, apenas interpretações é - como Nietzsche lucidamente reconheceu - uma interpretação, ela só poderá se realizar como resposta interessada a uma situação histórica determinada". ${ }^{14}$

$\mathrm{O}$ pensamento forte corresponde ao ideal moderno de abranger racionalmente toda a realidade. Este gerou esforços para captar totalmente a realidade nas fórmulas e proposições universais. ${ }^{15}$ A modernidade, seguindo a perspectiva epistemológica que afirma a possível adequação da mente à realidade sendo possível então "capturá-la", fixou esta realidade de forma normativa, criando um acesso único a ela, só expresso adequadamente

\footnotetext{
${ }^{10}$ A expressão pensiero debole e suas variações (pensamento fraco ou débil) têm um sentido técnico no pensamento de Gianni Vattimo. Com esta expressão Vattimo indica uma profunda mudança ontológica e epistemológica com relação à modernidade, que se caracteriza por um pensamento forte. Para maior aprofundamento ver: VATTIMO, G.; ROVATTI, P. A. El pensamiento débil. Madrid: Ediciones Cátedra, 1998, pp. 18-42. A partir desse momento utilizaremos a expressão em português.

${ }^{11}$ VATTIMO, G.; RORTY, R. O futuro da Religião. Rio de Janeiro: Relume Dumará, 2006, p. 64.

${ }^{12}$ Ibid.

${ }^{13}$ Ibid., p. 65.

${ }^{14}$ Ibid.

${ }^{15}$ Cf. BURKHARD, J. J. Apostolicidade ontem e hoje: Igreja ecumênica no mundo pós-moderno. São Paulo: Loyola, 2008, p. 187.
} 
de maneira total, universal e unívoca. ${ }^{16} \mathrm{O}$ pensamento forte é, portanto, a característica epistemologia moderna. Ele encontra sua manifestação discursiva, como identificou Jean François Lyotard, na metanarrativa. ${ }^{17}$

Gianni Vattimo interpreta a crítica lyotardiana às metanarrativas como uma possibilidade de liberação dos "dialetos", resultante da afirmação positiva da diferença. ${ }^{18}$ Essa é a realização discursiva do pensamento fraco. Vattimo afirma: "se falo o meu dialeto, finalmente, num mundo de dialetos entre outros, se professo o meu sistema de valores - religiosos, estéticos, políticos, étnicos - neste mundo de culturas plurais, terei também uma consciência intensa da historicidade, contingência, limitação, de todos estes sistemas, a começar pelo meu". ${ }^{19}$ Aqui há um aprofundamento dos efeitos do pensamento fraco sobre a compreensão que o humano tem de si. A liberação de dialetos é um sinal sóciolinguístico de uma questão mais importante que a possibilidade de afirmar uma ontologia fraca. O pensamento fraco, que se expressa na multiplicidade dos dialetos, emerge de uma ontologia fraca.

Custa-nos a conceber esta oscilação como liberdade: a nostalgia dos horizontes fechados, ameaçadores e tranquilizadores ao mesmo tempo, continua ainda radicada em nós, como indivíduos e como sociedade. Filósofos niilistas como Nietzsche e Heidegger (mas também pragmatistas como Dewey ou Wittgenstein), ao mostrarem que o ser não coincide necessariamente com aquilo que é estável, fixo, permanente, mas tem antes a ver com o acontecimento, o consenso, o diálogo, a interpretação, esforçam-se por nos tornar capazes de alcançar esta experiência de oscilação do mundo pós-moderno como chance de um novo modo de ser (talvez: finalmente) humanos. ${ }^{20}$

\footnotetext{
${ }^{16}$ Isso pode ser facilmente verificado em diversas áreas do conhecimento moderno. Na filosofia esse fenômeno pode ser notado, por exemplo, nos sistemas de Karl Marx e George W. F. Hegel - ambos propositores de abordagens universais e totalizantes. Na política a totalização assumiu diversas formas: militarismo, colonialismo e imperialismo. De forma ainda mais contundente podemos citar também os totalitarismos nacionalistas como o Nazismo, Fascismo e o Socialismo Real. Comum a estes sistemas filosóficos e políticos são a eloquência e as narrativas fortes e totalizadoras que eles defendem. São sistemas erigidos a partir de metarrativas. Cf. BURKHARD, J. J. Op cit., pp. 187-189.

${ }^{17}$ Cf. LYOTARD, J. F. A Condição Pós-moderna. Lisboa: Gradiva Publicações, 2003.

${ }^{18}$ Cf. VATTIMO, G. A sociedade transparente. Lisboa: Relógio D'água, 1992, p. 15.

${ }^{19}$ Ibid., p. 15.

${ }^{20}$ Ibid., p. 17.
} 
Em suma, isso significa que no horizonte cultural que nos é próprio, somos convidados a interpretar a condição humana em termos fracos, não somente no que diz respeito a sua ação no mundo, mas, sobretudo, na sua existência como forma de ser-no-mundo. Que humano é que deve desenvolver sua jornada de forma espiritual? A esta pergunta só podemos responder: aquele que desde sua condição ontológica constitui-se como fraco, como débil. Isso significa dizer que na gênese do humano - lugar onde a espiritualidade pode ser desenvolvida - está uma ontologia dinâmica que prescinde de identidades fixas, constituindo-se como trama onde diversos e múltiplos fios se relacionam.

O telos do pensamento fraco, portanto, é um mundo em que a ideia de uma 'essência' natural não coloque limites à liberdade. Tendo em mente tal teleologia, o pensamento fraco, como projeto de enfraquecimento, tem plena atualidade. Tal vigor apresenta à pós-modernidade um caminho de afirmação da diversidade. Nesse cenário o cristianismo identifica traços que lhe são constitutivos. Sobretudo, identifica a gênese mesmo de todo o processo de enfraquecimento do pensamento, que não é mais do que a história do enfraquecimento do ser que se revela no mistério cristão da encarnação, da kenosis.

A kenosis ${ }^{21}$, como categoria filosófica central do pensamento de Vattimo, é o lugar pós-moderno por excelência para a teologia cristã. Ela é o princípio de uma nova ontologia: de uma ontologia do enfraquecimento. É isso que Vattimo propõe, perguntando de forma retórica: "Mas terá sentido pensar a

\footnotetext{
${ }^{21} \mathrm{Na}$ Chave linguística do Novo Testamento de Fritz Rienecker e Cleon Rogers, da Editora Vida Nova, encontramos a seguinte definição: "esvaziar, tornar vazio, tornar sem efeito. A palavra não significa que ele esvaziou-se de sua divindade, mas sim que ele esvaziou-se da manifestação da sua divindade [...] a palavra é uma expressão vívida da inteireza de sua auto-renúncia e sua recusa de usar o que ele tinha para seu próprio benefício" (p. 408). Uma significativa reflexão sobre o tema da kenosis na história da teologia do século XX pode ser encontrada em: ELWELL, W. A. (Ed.). Enciclopédia Histórico-Teológica da Igreja Cristã. Vol. II. São Paulo: Vida Nova, 1992, pp. 395-399. Na carta de Paulo aos Filipenses 4.6-8 encontramos o texto mais explícito sobre a temática da kenosis:

"Ele tinha a condição divina, e não considerou o ser igual a Deus como algo a que se apegar ciosamente.

Mas esvaziou-se a si mesmo, e assumiu a condição de servo, tomando a semelhança humana. $\mathrm{E}$, achado em figura de homem, humilhou-se e foi obediente até a morte, e morte de Cruz!".
} 
doutrina cristã da encarnação do filho de Deus como anúncio de uma ontologia do debilitamento?".22

A encarnação é a afirmação de que Deus se fez história e faz caminhada concreta com o povo. Desta forma todo distanciamento que a metafísica impôs sobre Deus - distanciamento legitimador dos processos violentos de controle e distribuição de sentido - é eliminado. Não que Deus se dissolva em pura imanência, mas antes, que a partir da kenosis, Ele se mostra na transparência ${ }^{23}$ de toda imanência. A total transcendência de Deus, bem como todos os mecanismos epistemológicos decorrentes dela, é superada. O Deus que "se fez homem em Jesus, mostrando, portanto, seu parentesco com e a natureza, ou ainda, como diríamos nós, inaugurando, assim, a dissolução da sua transcendência". ${ }^{24}$

No rastro desse Deus kenótico Vattimo encontra a expressão filosófica da pós-modernidade: "a encarnação, isto é, o rebaixamento de Deus ao nível do homem, aquilo que o Novo Testamento chama de kenosis de Deus, deverá ser interpretada como sinal de que o Deus não violento e não absoluto da época pósmetafísica tem como traço distintivo a mesma vocação para o debilitamento de que fala a filosofia de inspiração heideggeriana". ${ }^{25}$ A história da revelação da Deus na encarnação de Jesus mostra que não duas histórias, uma sagrada e outra profana, mas apenas uma. E esta é a nossa história humana. Ou melhor, as muitas histórias de homens e mulheres.

$\mathrm{Na}$ kenosis pode se encontrar a antecipação da cultura pós-moderna com seus traços distintivos. A "secularização [...] não deve ser entendida como um decréscimo ou uma despedida do cristianismo, mas como uma realização mais plena da sua verdade que é, recordemo-la, a kenosis, o rebaixamento de Deus, o desmentir dos traços 'naturais' da divindade". ${ }^{26}$ Portanto, não há qualquer contradição entre secularização e mensagem cristã, sobretudo se esta

\footnotetext{
${ }^{22}$ VATTIMO, G. Acreditar em acreditar. Lisboa: Relógio D’Água Editores, 1998, p. 27.

${ }^{23}$ Leonardo Boff trabalha o tema da experiência de Deus feita no interior do cristianismo estabelecendo uma comparação de três termos: transcendência, imanência e transparência. Depois de uma interessante reflexão acerca de como cada uma dessas categorias expressam certa ideia de Deus, L. Boff como em Jesus Cristo Deus não pode mais ser compreendido em chave transcendente nem imanente, mas, transparente. Ou seja, Deus a partir da encarnação se mostra na transparência de todas as coisas históricas, no espaço situado da cada cultura (BOFF, L. Experimentar Deus hoje. Petrópolis: Vozes, 1974, pp. 126-190).

${ }^{24}$ VATTIMO, G. Depois da Cristandade. São Paulo: Record, 2005, p. 40.

${ }^{25}$ VATTIMO, G. Acreditar em Acreditar, p. 30.

${ }^{26}$ Ibid., p. 39.
} 
é compreendida em sua dimensão mais radical. Desta forma "a encarnação de Jesus é ela mesma, acima de tudo, um fato arquetípico de secularização". ${ }^{27}$

Exatamente por isso, a encarnação de Deus é um rebaixamento, mas também uma doação de sentido à história. $O$ Deus que se rebaixa, quando o faz dá de si a homens e mulheres que podem encontrar em suas histórias sacralizadas, ou radicalmente dessacralizadas, a salvação que se anuncia sentido comunicado onde parecia só haver dogmatismos. O Deus kenótico inaugura um sentido fundado na eventualidade do Ser.

O tema da eventualidade do ser é muito importante nesse momento pois ele remete para a realidade que o humano só se realiza como tal à medida que acolhe o devir como processo, superando os esquemas fixistas onde a identidade é uma e a mesma definitivamente. Diante dessa dinâmica da eventualidade do ser, a relação é fundamental na construção da espiritualidade. Não se é humano nem espiritual na solidão, mas somente no evento que se constitui de relações.

Isso se expressa em sua forma mais radical na kenosis de Deus. A kenosis, que é enfraquecimento, trás à luz uma ontologia do enfraquecimento. Nesse sentido o Ser não é mais uma estrutura fixa a ser encontrada em determinado lugar a partir dos instrumentos da metafísica, mas um evento a ser celebrado no diálogo. Refletindo sobre tal temática G. Vattimo afirma o seguinte: “Quando nós pensamos que (1) o 'Ser' é um evento do logos, (2) o logos é 'diálogo', e (3) o diálogo é o momento do discurso intersubjetivo; então nossa preocupação ontológica é a de como ser capaz de 'encontrar' o Ser, não achar algo que já está lá, mas construir algo que mantém, que resiste ao tempo". ${ }^{28}$

É nesse contorno ontológico, de uma ontologia debole, que pensamos a espiritualidade como desenvolvimento do humano, não de qualquer humano lido em perspectiva metafísica, mas do humano que virtuosamente não cede à tentação de ser como os deuses: o humano com cheiro de terra. Nesse sentido ainda é preciso distinguir entre a hominização e a humanização, para só então falar sobre as dimensões da espiritualidade cristã que se inspira no caminho kenótico do Cristo de Deus.

\footnotetext{
${ }^{27}$ VATTIMO, G. Depois da Cristandade, p. 86.

${ }^{28}$ VATTIMO, G; RORTY, R. O futuro da Religião. Rio de Janeiro: Relume Dumará, 2006, p. 90 .
} 


\section{Dimensões da espiritualidade humanizada ou da humanidade espiritualizada}

O caminho da humanização passa, portanto, pela eventualidade que constitui nosso ser. Dizendo de outra maneira, a humanização depende das relações que travamos ao longo da existência. Isso significa dizer que a condição humana - e a espiritualidade por consequência - é estritamente relacional. Passar de uma mera hominização à vocação da humanização exige uma conversão tanto da mentalidade (dimensão racional) quanto das sensibilidades (dimensão empírica) diante da existência.

De um eu ensimesmado e estéril produzido pelo racionalismo fechado (e por sua razão forte), e sua separação sujeito-objeto, movesse a um nós

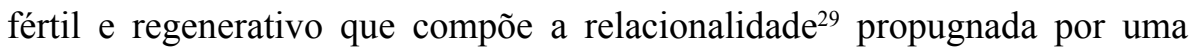
racionalidade aberta (marcada pelo pensamento fraco). Esse é o caminho que a pós-modernidade em sua reação à modernidade pode nos apresentar. É a relacionalidade quem pode recuperar a dimensão dialogal da razão. Ela se constitui, portanto, numa forma de ser no mundo que não é um estar num novo mundo, antes, um estar diferente no mesmo mundo: um estar em relação.

${ }^{29} \mathrm{O}$ conceito de relacionalidade como base para uma racionalidade aberta e integradora está apoiado no "pensamento relacional", matriz de pensamento característico do século XX. Dois autores se destacam no desenvolvimento do pensamento relacional: John Macmurray e Martin Buber. Buber é sem dúvida o mais conhecido, porém Macmurray tratou desse tema a partir da teologia cristã. Duas importantes obras suas são The self as Agent. London: Faber and Faber Limited, 1957. E Persons in Relation. London: Faber and Faber Limited, 1961. Na primeira obra Macmarray desafiou as idéias modernas sobre natureza humana e sujeito racional isolado, propondo no lugar um sujeito humano como agente de relações. Desta forma o acento no pensar (que pode ser restringido à interioridade) é substituído pelo agir que necessariamente deve levar em conta a exterioridade do ser. A pessoa não é seu pensamento isolado, mas sua ação integrada e integradora (Cf. MACMURRAY, J. The self as Agent. London: Faber and Faber Limited, 1957, pp. 56-80). No centro de seu conceito de pessoa está a relação como elemento constitutivo. Pelos atos - pessoa como agente - a relação é constituída. Como afirma Bukhard citando a obra Persons in Relation: "Macmarray introduziu a idéia da agência humana enquanto comunidade humana. O ser humano é estar em relação com outras pessoas". (BUKHARD, J J. Op Cit., p. 200). O outro autor que sustenta o conceito de "pensamento relacional" é Martin Buber. Notória é sua obra Ich und $D u$, traduzida para o português por Newton Aquiles Von Zuber e publicada no Brasil em 1980 por Editora Moraes com o título EU e TU. Buber faz uma importante distinção entre EU-TU e EU-Isso. EU-Isso equivaleria à fraturada relação sujeito/objeto, enquanto EU-TU é o princípio da relação como base de toda saber e, por fim da própria existência. O TU é sempre primordial no pensamento relacional, é na valorização plena do TU (que pode ser o TU pessoa, ou mesmo o TU divino) que nos fazemos humanos (BUBER, M. Eu e Tu. São Paulo: Editora Moraes, 1980). 
Falar dessa forma de ser no mundo - a relacionalidade -, é o mesmo que levantar a questão sobre a ampliação do conceito de racionalidade. Esta por sua vez depende da conversão da subjetividade: de uma subjetividade fechada sobre a estreiteza da racionalização, para uma subjetividade aberta ao outro (outros e Outro) e, portanto, à relação. De um fechamento em si é preciso caminhar para uma abertura à alteridade.

Como afirma Alfonso Garcia Rubio:

Fechado em si mesmo, o ser humano coisifica e instrumentaliza todo tipo de relação. Se for uma pessoa religiosa, aceitará Deus só na medida em que este responde à sua expectativa. Utiliza o divino apenas para o interesse próprio, tal como utiliza as relações com os seres humanos. O outro só é "aceito" quando pode responder às suas necessidades; e o seu relacionamento com a natureza também é meramente utilitário. Não é percebido nem celebrado o simbolismo que ela contém. Quer dizer, o outro (Deus, homem, mulher, filho etc.) não é aceito como outro (...) predomina, na subjetividade fechada, a rejeição do outro como outro (...) a subjetividade fechada instaura e desenvolve relações desumanizantes, leva à morte do outro e ao desastre ecológico. ${ }^{30}$

É preciso, portanto, superar essa subjetividade fechada geradora de "relações desumanizantes" e, experimentar uma nova subjetividade que nos permita aceitar a proposta relacional como nova forma de ser no mundo.

Na subjetividade aberta, o ser humano vivencia a alteridade, isto é, o reconhecimento, a aceitação e a valorização do outro, na sua diferença. Comporta superação do medo do que seja diferente e do narcisismo. Na relação com Deus, a pessoa é capaz de abrir-se à sua novidade, de aceitar a transcendência e de acolher a sua interpelação. Supera a tentação de medir Deus segundo a expectativa humana. Deus não é manipulado nem instrumentalizado. Na relação com ele, o ser humano pode encontrar respostas às carências de ser criado (...) A pessoa, nas suas relações interpessoais, se abre aos outros seres humanos, respeitados e aceitos como diferentes (...) Na relação com o meio ambiente, a pessoa supera a perspectiva meramente utilitária e mecanicista (...) Mediante um processo lento e nada fácil - identificado com o processo de humanização - a pessoa vai aprendendo a se abrir

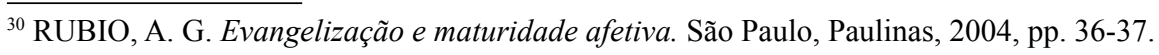


ao outro (Deus, mulher, homem, filho), respeitando-o e aceitando-o como diferente. ${ }^{31}$

A relacionalidade como forma de ser no mundo tem um grande desafio que é a integração daquilo que foi cindido pelo dualismo cartesiano. A distinção que Descartes faz entre possuir um corpo (res extensa) e ser uma alma (razão, res cogitans) constitui a base para a afirmação de uma racionalidade estreita, que se consuma em certa dimensão da existência (alma/ razão - res cogitans) que pode precindir sem nunhuma hesitação de outras dimensões (corpóreo-afetivas - res extensa). Essa visão dualista reifica a razão em detrimento da corporeidade e de seus sentidos. "Muitas experiências anularam, paulatinamente, todo crédito que eu dera aos sentidos (...) encontrei equívocos baseados nos juízos exteriores. E não apenas nos exteriores, mas também nos interiores". ${ }^{32}$ Neste sentido Descartes pôde reduzir o corpo à figura de uma máquina.

E como um relógio constituido de rodas e contrapesos não observa menos exatamente todas as leis da natureza quando é mal feito, e quando não mostra bem as horas, do que quando satisfaz inteiramente o desejo do artífice; da mesma forma também, se considero o corpo do homem uma máquina de tal maneira construída e constituída de ossos, nervos, músculos, veias, sangue e pele, que, mesmo que não existisse nele espírito algum, não deixaria de se mover de todas as maneiras que faz agora, quando não se move pela direção de sua vontade, nem, por conseguinte, pela ajuda do espírito, mas apenas pela disposição dos orgãos. ${ }^{33}$

A visão de superioridade da alma pensante (res cogitans) frente ao corpo destituído da sacra dignidade conferida pela razão (res extensa) fica patente a partir da imagem do relógio como máquina que ele usa para falar do corpo humano. Essa superioridade pode ser ainda melhor vista a partir da seguinte afirmação de Descartes:

Mas acontece exatamente o contrário com as coisas corpóreas ou extensas, já que não exista uma sequer que eu não faça facilmente em pedaços com o meu pensamento, que meu espírito não divida com facilidade em

\footnotetext{
${ }^{31}$ RUBIO, A. G. Op. Cit., pp. 37-38.

${ }^{32}$ DESCARTES, R. Meditações. São Paulo: Nova cultural, 2000, p. 318.

${ }^{33}$ Ibid, p. 328.
} 
muitas partes e, por conseguinte, que eu não reconheça ser divisível. E isso seria suficiente para ensinar-me que o espírito ou a alma do homem é completamente diferente do corpo, se já não tivesse aprendido em outros lugares. ${ }^{34}$

Res cogitans e res extensa não podem ser dimensões colocadas em posição hierárquica, mas articuladas numa dinâmica integradora. Carlos Palácio percebe bem essa cisão entre sujeito e objeto operada pela razão instrumental.

Ao afirmar de maneira absoluta a primazia do lógico sobre o ser, a razão moderna privilegiou a perspectiva do sujeito que impõe à realidade o seu código interpretativo. $\mathrm{O}$ resultado foi a ruptura nunca mais superada entre sujeito e objeto, com todos os seus desdobramentos, e o isolamentos em si mesmo de um sujeito auto-centrado, não dialogal. ${ }^{35}$

Ressaltando a profunda crise da razão instrumental - pensamento forte - preconizada pelo dualismo cartesiano, Palácio aponta precisamente a sua extensão, ao mesmo tempo em que o campo onde a batalha de superação de tal cisão deve se dar: a antropologia. Segundo ele "para sair desta aporia não basta fazer uma crítica do conhecimento, mesmo em nome de uma 'razão comunicativa'. É preciso descer até a antropologia que sustenta a pretensão absoluta da razão moderna". ${ }^{36}$

Deslocar o problema da cisão sujeito/objeto para o campo da antropologia é dar a concretude necessária a ele. Desta forma, tal cisão não simplesmente uma questão epistemológica, mas uma questão histórico-existencial, campo onde a teologia encontra seu chão próprio. Palácio conclui seu argumento afirmando que "o ser humano é constitutivamente dialogal, um 'eu' ante um 'tu'. Ser relacional em si mesmo". ${ }^{37}$

A ascensão do outro como um "tu" diante do "eu" é exatamente o que assumimos como princípio da relacionalidade. Princípio que deve ser a base para uma racionalidade aberta e integradora. Partindo da realidade do humano como ser dialogal deve-se chegar a uma epistemologia adequada a

\footnotetext{
${ }^{34}$ Ibid, p. 329.

${ }^{35}$ PALÁCIO, C. Novos paradigmas ou fim de uma era teológica?. In: ANJOS, M. F. Teologia Aberta Ao Futuro. São Paulo: Loyola, 1997, p. 94.

${ }^{36}$ Ibid.

${ }^{37}$ Ibid.
} 
tal dialogicidade. Isto é, uma perspectiva sobre o conhecimento que opere o descentramento da razão. Não para negá-la, mas para transgredi-la, para ir além ${ }^{38}$. Citando ainda C. Palácio:

O primigênio na experiência humana não é o cogito que isola, o pensar autocentrado, mas o ser pensado por alguém. E, portanto, ser amado. De modo que o cogito ergo sum cartesiano poderia e deveria ser transcrito como amor ergo sum. Só um ser humano constitutivamente relacional é capaz de superar a aporia do "conhecimento sem amor". ${ }^{39}$

Para falar de relacionalidade - da ascensão do outro não mais como objeto, antes como sujeito de todo processo de conhecimento e existência - é necessário mostrar que esse movimento exige uma conversão na concepção de subjetividade. Esta conversão pode ser compreendida como um descentramento. Não como uma forma de auto-negação, nem tampouco nenhum tipo de pessimismo radical mais ou menos influenciado por matrizes intelectuais e religiosas de corte dualista.

Descentrar-se é um convite a um encontro mais profundo com o outro, que em última análise só pode acontecer, se no nível ontológico a uma abertura ao diferente. Nesse sentido uma ontologia fraca é o fundamento de uma subjetividade aberta que proporciona a relação. É uma relação que tem inicio na própria interioridade, mas que só se mantém na medida em que se abre à alteridade. Este seria o passo limiar para a construção de uma racionalidade mais aberta, que consiga integrar outras dimensões da existência humana no processo de conhecimento da realidade.

A dimensão de imanência deve ser articulada em conjunto com a dimensão de transcendência. Interioridade e alteridade devem se iluminar mutuamente, corrigindo-se e afirmando-se. Por um lado é certo que a pessoa é chamada a se auto-possuir e desenvolver sua própria finalidade. ${ }^{40}$ Porém, isso

\footnotetext{
${ }^{38}$ Ibid., p. 95.

${ }^{39}$ Ibid.

${ }^{40} \mathrm{Cf}$. RUBIO, A. G. Unidade na pluralidade: o ser humano à luz da fé e da reflexão cristãs. São Paulo: Paulinas, 2000, p. 309. Alfonso Garcia Rubio propõe como traços constitutivos da pessoa humana as seguintes características: “Autopossessão: a pessoa se autopertence, possui autonomia própria no nível ôntico (...). Conseqüência: a pessoa não é propriedade de outro. Liberdade e responsabilidade: a pessoa é capaz de escolher determinados valores por si mesma. (...) é chamada a ser livre (...). Conseqüência: repugna à dignidade da pessoa todo o tipo de manipulação. Perseidade: a pessoa tem em si a sua própria finalidade. No seu agir, a pessoa, acima de tudo, se auto-realiza como ser pessoal (...). Conseqüência: a pessoa não é um objeto
} 
não pode justificar um auto-centramento que isole a pessoa num fechamento ao entorno de seus próprios interesses, projetos e aspirações.

Esse movimento rumo à alteridade, uma vez iniciado a partir de uma interioridade salutarmente fortalecida, opera a plena humanização. Homens e mulheres encontrados consigo à procura do encontro com o $\mathrm{O}(\mathrm{o})$ utro: isso é relacionalidade, e nesse caminho há possibilidade de afirmar uma espiritualidade que integre as diversas dimensões da realidade.

Esse caminho a uma espiritualidade relacional se dá numa circularidade elíptica onde as linhas tocam os extremos de um espaço. Há aí um encontro com o outro em todas as suas dimensões: o outro que é o mundo, o outro que é o irmão e aquele que é o totalmente Outro.

Abertura ao mundo - É verdade que a pessoa é qualitativamente diferente das coisas do mundo e da natureza, mas é igualmente certo que a pessoa humana, pessoa encarnada, forma parte também do mundo natural. É criatura entre as criaturas, unidas a todas as outras numa solidariedade fundamental. É verdade que a pessoa humana, imagem de Deus, é chamada a trabalhar o mundo para transformá-lo em morada digna dos homens (todos); mas trata de um relacionamento que deve ser vivido responsavelmente e deve sempre estar penetrado do respeito às leis que regem o dinamismo do ecossistema do qual o homem é parte. ${ }^{41}$

$\mathrm{O}$ homem e a mulher enquanto pessoas o são no mundo em sua representação como cultura ou natureza. Certa racionalidade instrumental e estreita operou um divórcio entre a pessoa e seu mundo, tornando-o estranho e, portanto, sujeito à exploração e subjugação. Numa proposta de humanização e relacionalidade esse divórcio deve ser superado. Um reencontro de homens e mulheres com o mundo (natureza/cultura) é urgente.

O testemunho que a fé nos comunica revela a dimensão criatural da natureza, ou seja, há uma intencionalidade amorosa na origem de todas as coisas. Isso foi experimentado na tradição cristã de forma clara e profunda tanto na reflexão teológica, quanto na experiência mística. A Laudato si pontua com clareza a identidade criacional de tudo que existe:

Na tradição judaico-cristã, dizer "criação" é mais do que dizer natureza,

ou um instrumento para ser usado e depois deixado de lado (...) viver puramente em função do outro, descuidando sua autofinalidade, aliena a pessoa, desumanizando-a". Cf. RUBIO, A. G. Unidade na pluralidade, p. 308.

${ }^{41}$ RUBIO, A. G. Unidade na pluralidade, p. 310. 
porque tem a ver com um projeto do amor de Deus, onde cada criatura tem um valor e um significado. A natureza entende-se habitualmente como um sistema que se analisa, compreende e gere, mas a criação só se pode conceber como um dom que vem das mãos abertas do Pai de todos, como uma realidade iluminada pelo amor que nos chama a uma comunhão universal. $^{42}$

Tal aproximação à natureza como criação, na perspectiva do Papa Francisco, é marcada por uma dupla postura: por um lado é reverente, uma vez que "a criação pertence à ordem do amor. O amor de Deus é a razão fundamental de toda a criação" ${ }^{43}$; por outro lado é desmistificadora, à medida que como criação a natureza não é deificada, mas pode se constituir como lugar analógico para falar o mistério criador, que contará sempre com a criatividade e responsabilidade humana. "Sem deixar de a admirar pelo seu esplendor e imensidão, já não lhe atribui um carácter divino. Deste modo, ressalta ainda mais o nosso compromisso para com ela". ${ }^{44}$

Abertura aos outros - A liberdade, autonomia e autofinalidade da pessoa se realiza na relação, no diálogo, no encontro, na abertura aos outros seres pessoais. Sair de si para o encontro (em diversos níveis) é constitutivo da pessoa. ${ }^{45}$

Essa abertura ao outro é um aspecto dos mais centrais no processo de afirmação de uma racionalidade aberta, onde o esquema sujeito/objeto é superado por uma intersubjetividade muito mais fecunda. ${ }^{46}$ Efetivamente nosso parâmetro de percepção da realidade sensível é o outro, aquele que pode nos interpelar, do qual não podemos escapar à sua face. ${ }^{47}$ Mas não somente

${ }^{42}$ FRANCISCO. Laudato si. Louvado sejas, sobre o cuidado da casa comum. São Paulo: Paulus. São Paulo: Loyola, 2015, p. 51.

${ }^{43}$ Ibid., p. 51.

${ }^{44}$ Ibid., p. 52.

${ }^{45}$ RUBIO, A. G. Unidade na pluralidade, p. 310.

${ }^{46}$ Esse "outro" não é somente uma pessoa, é também uma sociedade, uma comunidade, um coletivo. Isso coloca o encontro com esse outro em diversos níveis. Há o nível personalista, mas também o nível sociopolítico. É exatamente esse último que tem sido mais desprezado ao longo da história da teologia.

${ }^{47}$ Acerca da temática da imersão do outro como parâmetro para novas relações éticas (alteridade), é determinante o pensamento de Emmanuel Levinas, sobretudo na obra Totalité et Infini. Aqui citaremos a tradução de José Pinto Ribeiro: LÉVINAS, E. Totalidade e Infinito. Lisboa: Edições 70, 1980. Nesta obra merece destaque a terceira secção $O$ rosto e a Exterioridade, onde Levinas trata especificamente do tema da ética e sua relação com a face do outro, propondo 
da realidade sensível, a percepção do próprio desvelamento divino passa pelo reconhecimento do outro.

O escritor da primeira carta de João leva essa centralidade referencial da presença de Deus na face do outro às últimas conseqüências, àquelas de nível soteriológico e escatológico. "O que ama o seu irmão permanece na luz, e nele não há ocasião de queda"48. E ainda: "Nós sabemos que passamos da morte para a vida porque amamos os irmãos" ${ }^{49} \mathrm{E}$ por fim:

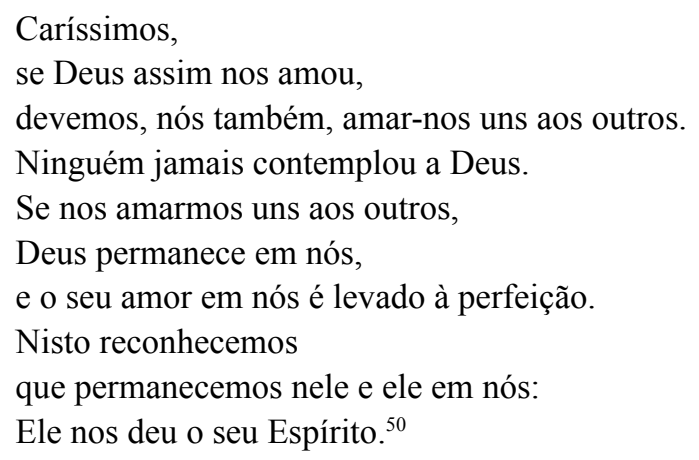

Abertura a Deus - "É o aspecto mais fundamental da pessoa [na perspectiva teológica] (...) Deus estabelece uma relação dialógica com o ser humano; só o ser humano pode falar com Deus e aceitar a sua proposta. A relação com Deus, relação única e exclusiva faz de cada individuo humano uma pessoa e não apenas mais um individuo da espécie humana". ${ }^{51}$

Essa relação primordial com Deus dá a base para as demais relações. Todo o processo de afirmação de uma racionalidade aberta à realidade sensível, que se concretiza na relacionalidade passa por essa relação fontal com Deus. Contudo, tal relação deve caminhar para a maturidade, afim de que certas imagens distorcidas da divindade não acabem comprometendo uma relação profunda e vivificante.

No sentido de evitar possíveis armadilhas inerentes ao desafio da relação

desta forma uma filosofia da alteridade (pp. 167-232). Além desta obra, ver também LÉVINAS, E. De Deus vem a idéia. Petrópolis: Vozes, 2001; LÉVINAS, E. Entre nós. Ensaios sobre a alteridade. Petrópolis: Vozes, 2005.

${ }^{48} 1$ João 2. 10.

49 João 3.14.

${ }^{50} 1$ João 4. 9-13.

${ }^{51}$ RUBIO, A. G. Unidade na pluralidade, p. 311. 
com Deus, é válido considerar a reflexão proposta por Leonardo Boff em seu livro Experimentar Deus. A transparência de todas as coisas. Ele identifica três momentos presentes na experiência de fé. O primeiro momento ele chama de "saber-imanência-identificação". Nele, "a palavra está a serviço do que experimentamos de Deus. Fixamos uma representação. Inicialmente não temos ainda consciência de que se trata apenas de uma representação daquilo que não pode ser representado". 52

Deus é identificado com os conceitos que dele fizemos. Ele habita nossos conceitos e nossas linguagens. Elaboramos doutrinas sobre Deus e sobre o mundo divino, doutrinas que se encontram nos vários credos e nos catecismos. Com tal procedimento tentamos encher de sentido último e pleno nossa vida. Deus pode ser encontrado na intimidade do coração. ${ }^{53}$

O segundo momento, que Boff chama de "não-saber-transcendênciadesidentificação", é caracterizado quando, pela experiência de Deus, damo-nos conta da insuficiência de todas as imagens de Deus. Tudo o que dele dizemos é figurativo e simbólico. Ele está para além de todo o nome e desborda de todo o conceito.

Pode surgir uma teologia da morte de Deus: decreta a morte de todas as palavras referidas ao divino, porque elas mais escondem do que comunicam Deus. Não sabemos mais nada; desidentificamos Deus das coisas que dizemos dele. Por aí entendemos o lema dos mestres zen: "Se encontrares Buda, mata-o". Se encontrares Buda, não é o buda - é apenas sua imagem. Mata a imagem para estares livres para o encontro com o verdadeiro Buda. ${ }^{54}$

Logo após este momento transitório de relativização de um discurso teológico cristalizado, L. Boff diz que:

Num terceiro momento da experiência de Deus, reabilitamos as imagens de Deus. Após tê-las afirmado (A), tê-las negado (B), agora criticamente nos reconciliamos com elas. Assumimo-las como imagens e não mais

\footnotetext{
${ }_{52}$ BOFF, L. Experimentar Deus. A transparência de todas as coisas. $3^{\mathrm{a}}$ ed. Petrópolis: Vozes, 2002, p. 13.

${ }^{53}$ Ibid.

${ }^{54}$ Ibib., p. 15.
} 
como a própria identificação de Deus. Compreendemos que nosso acesso a Deus só pode ser feito através das imagens. Começamos a saboreá-las porque estamos livres diante delas. Elas são andaimes, não a construção, e as acolhemos como andaimes. ${ }^{55}$

No processo de abertura a Deus, que constitui elemento importante da humanização, o alvo deve ser a maturidade de uma relação que perceba a total alteridade do mistério fontal de tudo aquilo que existe.

\section{Conclusão}

Pensar a antropologia como locus da espiritualidade cristã à luz do evento kenótico é o que este artigo buscou fazer. Num momento em que o tema da espiritualidade ocupa um papel importante não somente na cena religiosa, mas também nos espaços públicos, considerá-la de maneira não dualistas é imprescindível.

A vocação à humanidade se revela como caminho a ser percorrido. Criados com potencial da humanidade somos todos convocados ao longo da vida ao desenvolvimento pleno desse chamado. Assumir tal vocação como projeto é a aventura existencial de cada homem e mulher. Nisto a espiritualidade se revela como maturidade que encontra no caminho e se realiza no caminhante.

Pensar a existência como projeto é perceber que na gênese do humano está uma ontologia fraca, ou seja uma indeterminação fundamental que faz do devir a qualidade do caminhante. Como projeto, a humanização está para cada um como potência. À medida que colocamos em ato tal potência a espiritualidade se faz cada vez mais amadurecida.

Tal amadurecimento humano, que no artigo compreendemos como espiritualidade, pode ser verificado no que chamamos de "dimensões da espiritualidade humanizada ou da humanidade espiritualizada". É na relação que todo potencial se desdobra em ato concreto. É no encontro do ser consigo mesmo, com o outro, com Deus e com a realidade, que a vocação à humanidade se revela. E é exatamente aí que que encontramos nossa maior densidade: nossa espiritualidade.

${ }^{55}$ Ibid., pp. 15-16. 


\section{Referências bibliográficas}

BOFF, L. Experimentar Deus. A transparência de todas as coisas. $3^{\mathrm{a}}$ ed. Petrópolis: Vozes, 2002.

BOFF, L. Experimentar Deus hoje. Petrópolis: Vozes, 1974.

BONDER, N. Código penal celeste: prepare sua defesa diante do Tribunal Supremo. Rio de Janeiro: Elsevier, 2004.

BUBER, M. Eu e Tu. São Paulo: Editora Moraes, 1980.

BURKHARD, J. J. Apostolicidade ontem e hoje: Igreja ecumênica no mundo pós-moderno. São Paulo: Loyola, 2008.

COX, H. Que a serpente não decida por nós. Rio de Janeiro: Civilização Brasileira, 1970.

DESCARTES, R. Meditações. São Paulo: Nova cultural, 2000.

ELWELL, W. A. (Ed.). Enciclopédia Histórico-Teológica da Igreja Cristã. Vol. II. São Paulo: Vida Nova, 1992.

FRANCISCO. Laudato si. Louvado sejas, sobre o cuidado da casa comum. São Paulo: Paulus. São Paulo: Loyola, 2015.

LÉVINAS, E. De Deus vem a idéia. Petrópolis: Vozes, 2001.

LÉVINAS, E. Entre nós. Ensaios sobre a alteridade. Petrópolis: Vozes, 2005.

LEVINAS, E. Totalidade e Infinito. Lisboa: Edições 70, 1980.

LYOTARD, J. F. A Condição Pós-moderna. Lisboa: Gradiva Publicações, 2003.

MACMURRAY, J. Persons in Relation. London: Faber and Faber Limited, 1961.

MACMURRAY, J. The self as Agent. London: Faber and Faber Limited, 1957.

MORANO, C. D. Crer depois de Freud. São Paulo: Loyola, 2003.

PALÁCIO, C. "Novos paradigmas ou fim de uma era teológica?". In: ANJOS, M. F. Teologia Aberta Ao Futuro. São Paulo: Loyola, 1997.

REINECKER, F.; ROGERS, C. Chave lingüistica do Novo Testamento. São Paulo: Vida Nova, 1995.

RUBIO, A. G. Evangelização e maturidade afetiva. São Paulo, Paulinas. 2004.

RUBIO, A. G. Unidade na Pluralidade: O ser humano à luz da fé e da reflexão cristãs. São Paulo: Paulinas, 2000.

UNAMUNO, M. Do sentimento trágico da vida. São Paulo: Martins Fontes, 2000. 
VATTIMO, G. Acreditar em acreditar. Lisboa: Relógio D’Água Editores, 1998.

VATTIMO, G. A sociedade transparente. Lisboa: Relógio D’água, 1992.

VATTIMO, G. Depois da Cristandade. São Paulo: Record, 2005.

VATTIMO, G.; RORTY, R. O futuro da Religião. Rio de Janeiro: Relume Dumará, 2006.

VATTIMO, G.; ROVATTI, P. A. El pensamiento débil. Madrid: Ediciones Cátedra, 1998.

WÉNIN, A. O Homem Bíblico. Leituras do Primeiro Testamento. São Paulo: Loyola, 2015.

WOLFF, H. W. Antropologia do Antigo Testamento. São Paulo: Hagnos, 2007.

Alessandro Rocha

Doutor em Teologia pela Pontifícia Universidade Católica do Rio de Janeiro

Professor de Graduação e Pós-Graduação na Faculdade Unida

Professor da Faculdade Evangélica das Assembleias de Deus

(FAECAD)

Rio de Janeiro / RJ - Brasil

E-mail: souprotestante@gmail.com 